\title{
Ultrasonic Characterization of Potting Voids (An Interim Report)
}

\author{
M. Quarry, G. Thomas
}

April 23, 2001

U.S. Department of Energy

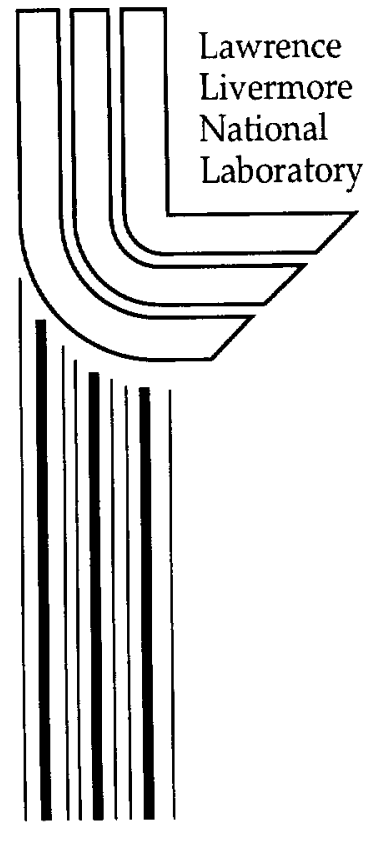




\section{DISCLAIMER}

This document was prepared as an account of work sponsored by an agency of the United States Government. Neither the United States Government nor the University of California nor any of their employees, makes any warranty, express or implied, or assumes any legal liability or responsibility for the accuracy, completeness, or usefulness of any information, apparatus, product, or process disclosed, or represents that its use would not infringe privately owned rights. Reference herein to any specific commercial product, process, or service by trade name, trademark, manufacturer, or otherwise, does not necessarily constitute or imply its endorsement, recommendation, or favoring by the United States Government or the University of California. The views and opinions of authors expressed herein do not necessarily state or reflect those of the United States Government or the University of California, and shall not be used for advertising or product endorsement purposes.

This work was performed under the auspices of the U.S. Department of Energy by the University of California, Lawrence Livermore National Laboratory under Contract No. W-7405-Eng-48.

This report has been reproduced directly from the best available copy.

Available electronically at http://www.doc.gov/bridge

Available for a processing fee to U.S. Department of Energy

And its contractors in paper from

U.S. Department of Energy

Office of Scientific and Technical Information

P.O. Box 62

Oak Ridge, TN 37831-0062

Telephone: (865) 576-8401

Facsimile: (865) 576-5728

E-mail: reports@adonis.osti.gov

Available for the sale to the public from

U.S. Department of Commerce

National Technical Information Service

5285 Port Royal Road

Springfield, VA 22161

Telephone: (800) 553-6847

Facsimile: (703) 605-6900

E-mail: orders@ntis.fedworld.gov

Online ordering: http://www.ntis.gov/ordering.htm

\section{OR}

Lawrence Livermore National Laboratory

Technical Information Department's Digital Library

http://www.llnl.gov/tid/Library.html 
Ultrasonic Characterization of Potting Voids

(An interim report)

By

Mike Quarry and Graham Thomas 


\section{Objective}

This interim report summarizes the efforts to date to develop an ultrasonic technique for detecting and sizing potting voids between a high explosive material and a metallic backing. This report presents the results for two tasks. The first task was to establish that ultrasonic energy penetrates LX-17. Then once the acoustic properties of LX-17 were measured, a demonstration experiment substantiated that voids could be detected and imaged.

\section{Ultrasonic Properties Determination}

Initial studies have focused on the development of a suitable ultrasonic mock material for detecting voids. To determine a suitable material for the mock of LX-17, ultrasonic material properties were measured at the High Explosives Application Facility with the assistance of Scott Groves and Bruce Cunningham. Samples of LX-17 with various diameters and thickness were studied.

Four properties must be obtained to characterize the ultrasonic properties of LX17. They are density, longitudinal wave velocity, shear wave velocity, and attenuation. A longitudinal wave has its particle motion in the direction of propagation, while a shear wave has particle motion transverse to the direction of propagation. A piezoelectric transducer was excited with a short pulse to produce a broadband ultrasonic pulse that propagates through the material. The sound wave reflects from the surfaces and bounces back and forth with attenuation at each bounce. The time of arrival between successive bounces is measure to determine the velocity in the material. This method eliminates errors in the system, as the time difference is only attributable to the propagation time through the thickness of the material. The experimental setup is shown in a picture in Figure 1. A water-soluble gel was used to couple ultrasound into the sample. Attenuation was measured at $2.25 \mathrm{MHz}$ by calculating the loss between successive echoes. This is not a precise measurement as there are as many sources of loss besides attenuation in this measurement, but the method should be sufficient for the purposes at hand. Appendix A contains a table that shows the data and calculations for the various samples measured. Note that the LX-17 samples had fairly uniform acoustic properties for the various ages.

Once the material properties were obtained, a search was done for a mock material with similar properties. Plexiglas and Lexan were identified as potential candidates for a mock material. Table 1 shows a list of the material properties as compared to LX-17. Plexiglas was chosen as the mock material because it is closer in most acoustic properties and is easier and cheaper to obtain. Plexiglas has a slightly lower attenuation, but this can be accounted for by increasing the thickness. Void detection depends on the amplitude of an acoustic reflection, which results from the mismatch in impedance between the materials of the interface. Air has very low acoustic impedance and thus all of the acoustic energy is reflected at the Plexiglas to air interface. 
The reflection coefficients between APC 2.5 potting material and mock materials as well as LX-17 are shown in Table 1.

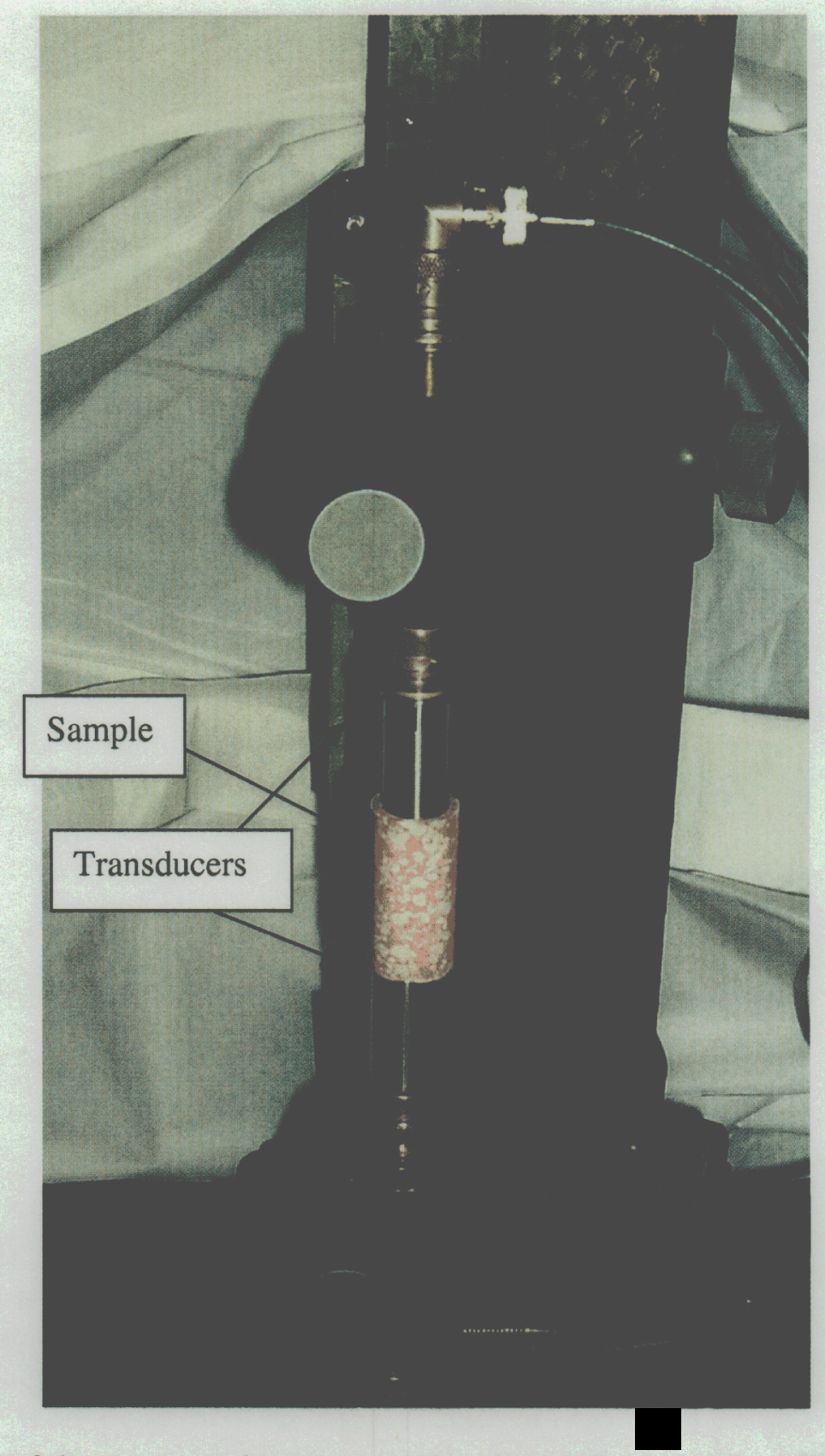

Figure 1. A picture of the setup used to measure the ultrasonic properties of LX-17. 
Table 1. Material Properties of Potential Mock Materials

\begin{tabular}{|c|c|c|c|c|c|}
\hline Material & $\begin{array}{c}\text { Density } \\
\left(\mathrm{kg} / \mathrm{m}^{3}\right)\end{array}$ & $\begin{array}{c}\text { Long. } \\
\text { Velocity } \\
(\mathrm{km} / \mathrm{s})\end{array}$ & $\begin{array}{c}\text { Shear } \\
\text { Velocity } \\
(\mathrm{km} / \mathrm{s})\end{array}$ & $\begin{array}{c}\text { Reflection } \\
\text { coefficient } \\
\text { with APC } *\end{array}$ & $\begin{array}{c}\text { Attenuation } \\
(\mathrm{dB} / \mathrm{m}) \text { at } \\
2.25 \mathrm{MHz}\end{array}$ \\
\hline LX-17 & 1.88 & 2.71 & 1.31 & 0.65 & 350 \\
\hline Plexiglas & 1.18 & 2.72 & 1.68 & 0.50 & 280 \\
\hline Lexan & 1.20 & 2.30 & 1.10 & 0.44 & 800 \\
\hline
\end{tabular}

* Note: the reflection coefficient with air is approximately 1.

Materials for a mock sample were obtained and assembled by bolting the Plexiglas and steel layers together and pouring the APC 2.5 into the gap. Shims were inserted into the APC to simulate voids. Drilling a hole in the Plexiglas, introducing air into the APC 2.5 and allowing it to cure also simulated voids. The size of the sample is roughly 6 " $\times 6$ ". Figure 2 shows a schematic side view of the sample. A photograph of the sample is shown in Figure 3. A large triangle void formed by inserting a shim provides a measure of resolution on a continuous scale. Figure 4 shows a close-up of the voids.



Figure 2. Schematic Side View of the Mock Sample. 


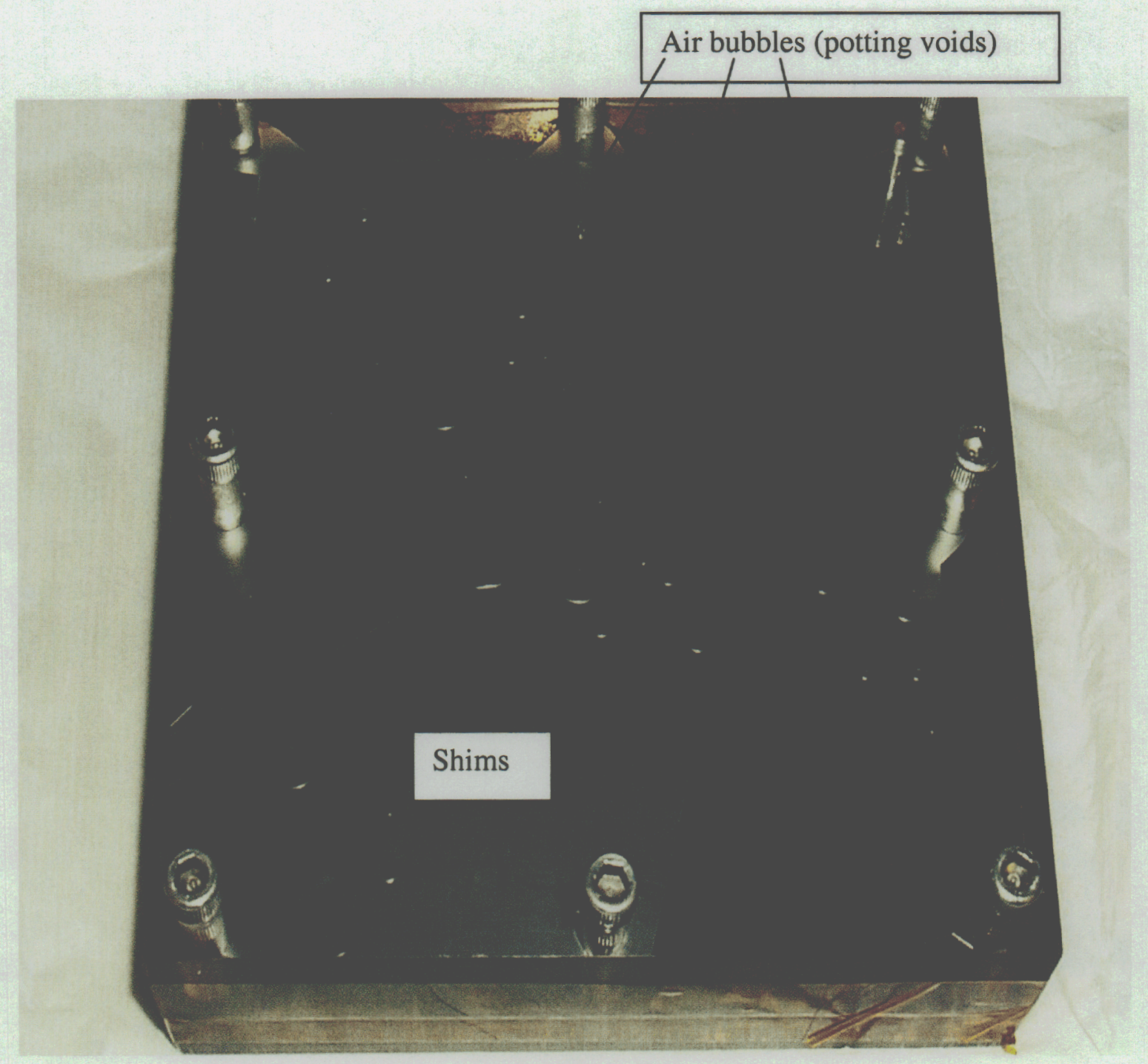

Figure 3. A photograph of the sample with voids created by injecting air through a hole. This technique produces a mock specimen that represents a realistic configuration. Void sizes range from $0.2 \mathrm{~mm}$ to $10 \mathrm{~mm}$. The overall sample size is 6" $\mathrm{6} 6$ ". 


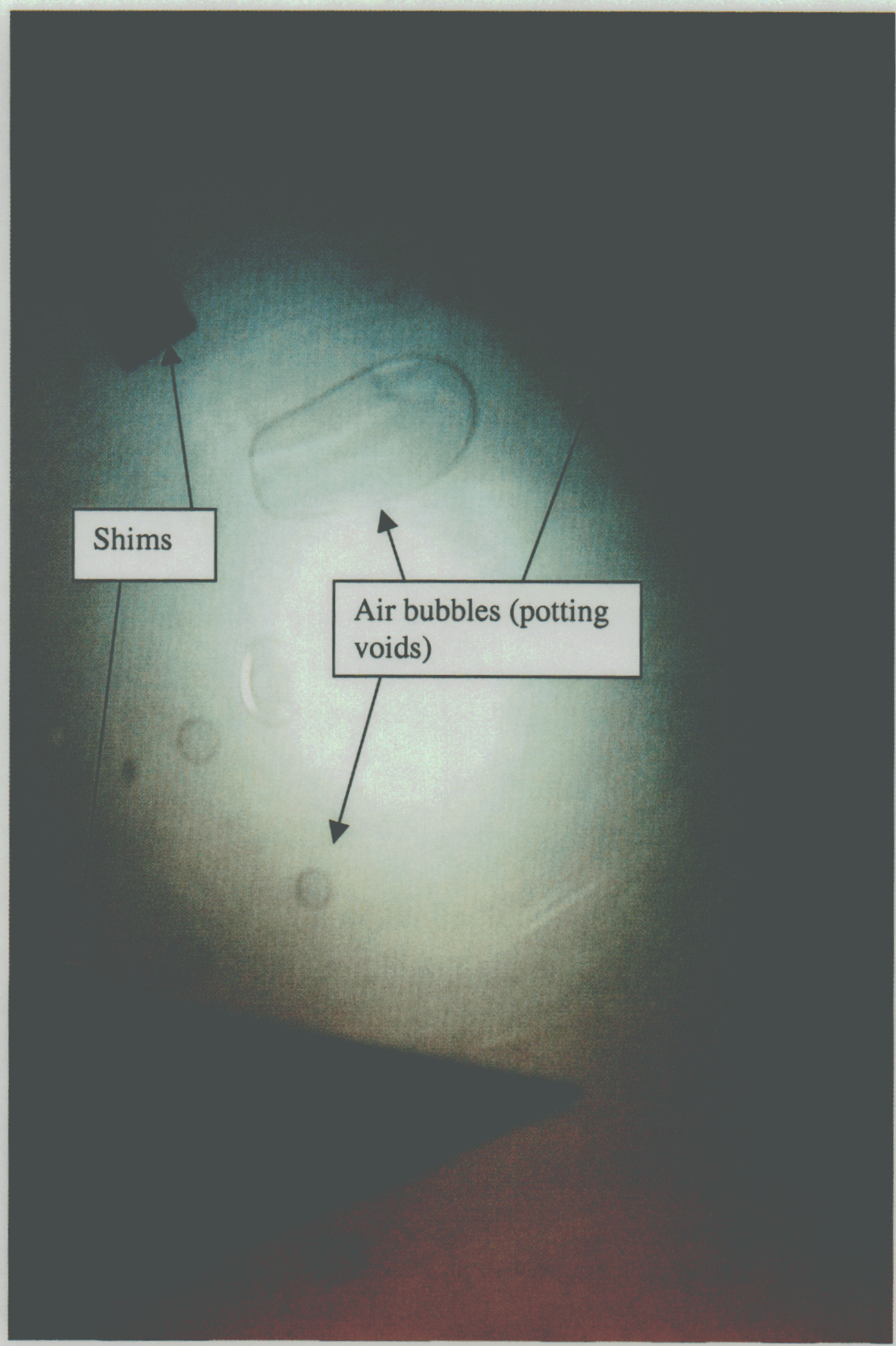

Figure 4. A close-up picture of the sample showing the round voids and straight edge voids. Note: the air bubbles differ in size from about $0.2 \mathrm{~mm}$ to $10 \mathrm{~mm}$ in diameter. 


\section{Experimental Results}

The goal of this initial study was to demonstrate the feasibility of ultrasonically imaging potting voids under a layer of LX-17. An experiment was performed with a $2.25 \mathrm{MHz}$ focused transducer on a surrogate sample. Data was taken at this frequency, because it was shown previously that $2.25 \mathrm{MHz}$ easily penetrates $\mathrm{LX}-17$. We plan to duplicate the experiment at higher frequencies that will yield improved resolution if attenuation does not severely limit penetration. The sample was placed in a tank of water and a $\mathrm{C}$-scan image was generated of the potting layer. Appendix $\mathrm{B}$ describes the ultrasonic $\mathrm{C}$-scan technique. Potting voids have a greater reflection coefficient than filled areas and thus produce a stronger ultrasonic reflection. Voids are displayed by mapping the signal amplitude to a color scheme that displays the differences in amplitude. Total delamination in an area of the sample produces a signal similar to a void.

Another ultrasonic imaging technique is called the B-scan. The B-scan is a cross section view of the component at a single slice plane orthogonal to the $\mathrm{C}$-scan plane. We did not generate B-scans of this specimen since we already knew the depth of the APC layer.

The surrogate Plexiglas specimen yielded an ultrasonic C-scan image that clearly displays voids in the APC 2.5 potting. Figure 5 shows an image of the specimen obtained at $2.25 \mathrm{MHz}$. There is an excellent match between the voids and delaminations displayed in the photograph and the ultrasonic image. Also delaminations of varying degree can be seen around the edges and particularly in the top right hand corner. Delaminations occurred near the edges as a result of the fill hole for pouring the APC 2.5. Voids of slightly less than $1 \mathrm{~mm}$ in diameter show up in the C-scan image. 




Figure 5. An ultrasonic C-scan of the sample at $2.25 \mathrm{MHz}$ with a photograph of the sample. Note that delaminations, air bubbles, and shims were detected.

\section{Concluding Remarks}

This interim report summarizes the ultrasonic efforts to detect and size potting voids. Ultrasonic velocity and attenuation measurements have demonstrated that it is practical for acoustic energy at $2.25 \mathrm{MHz}$ to propagate through LX-17. Plexiglas was found to be a adequate mock material for ultrasonic purposes. A sample with Plexiglas as the surrogate material was fabricated with potting voids. Ultrasonic images of this specimen demonstrate that voids were easily discernible.

Our plan is to test the limits of the ultrasonic imaging by increasing the probe frequency until the energy does not penetrate the sample. At higher frequencies the smaller voids are detectable and the image resolution is improved. Also the ultrasonic signals contain additional information about the potting layer. Signal features such as amplitude and frequency content are being analyzed to better characterize the interface. For example, the thickness of the potting layer could be measured. The thickness of the potting layer is such that an echo from the APC/stainless steel interface superimposes in time on the echo of the Plexiglas/APC interface. The combined echoes interfere with one another based upon the frequency content of the beam, the wavelength in the APC, and 
the thickness of the APC layer. This interference can be used to determine the thickness of the APC layer.

We are fabricating a second surrogate specimen with Lexan instead of Plexiglas. The Lexan has a higher attenuation than LX-17 and is more difficult to penetrate. Thus if we can image through the Lexan, our ability to image through $\mathrm{LX}-17$ is assured.

Ultrasonic evaluation will also be performed through the metal substrate. This approach also has significance to the programs.

Once feasibility is demonstrated we plan to devise and implement schemes for inspecting components. Such a task involves scanner design, algorithm development, sensor selection, and ultrasonic coupling issues. 


\section{APPENDIX A}

Table of Measured Ultrasonic Properties of LX-17 and aged creep specimens.

\begin{tabular}{|l|c|c|c|c|c|c|}
\hline LX-17 Samples & Site 300 & New \#1 & Aged 90C & New \#2 & Aged 20C & Aged 50C \\
\hline $\begin{array}{l}\text { Thickness } \\
(\mathrm{mm})\end{array}$ & 6.98 & 4.34 & 4.34 & 2.54 & 2.54 & 2.54 \\
\hline $\begin{array}{l}\text { Density } \\
\left(\mathrm{kg} / \mathrm{m}^{3}\right)\end{array}$ & 1877 & 1893 & 1887 & 1891 & 1891 & 1891 \\
\hline $\begin{array}{l}\text { Longitudinal } \\
\text { Velocity } \\
(\mathrm{km} / \mathrm{s})\end{array}$ & 2.791 & 2.736 & 2.729 & 2.647 & 2.691 & 2.645 \\
\hline $\begin{array}{l}\text { Shear Velocity } \\
(\mathrm{km} / \mathrm{s})\end{array}$ & 1.323 & 1.305 & 1.498 & 1.494 & 1.511 & 1.512 \\
\hline $\begin{array}{l}\text { Young's } \\
\text { Modulus (Gpa) }\end{array}$ & 8.90 & 8.73 & 12.71 & 12.66 & 12.95 & 12.97 \\
\hline $\begin{array}{l}\text { Shear Modulus } \\
\text { (Gpa) }\end{array}$ & 3.28 & 3.23 & 4.24 & 4.22 & 4.32 & 4.32 \\
\hline
\end{tabular}




\section{APPENDIX B}

\section{Ultrasonic C-scan Technique}

The ultrasonic C-scan technique produces an image of a plane that is parallel to the surface. To do this a pulsed ultrasonic transducer is scanned over the component in a raster fashion so that the area of interest is covered. The amplitude of the ultrasonic signal is captured at uniform spatial intervals as the transducer moves over the component. This amplitude is mapped onto a color table and displayed as a pixel on a monitor. Thus each pixel on the monitor corresponds to a location in the selected plane inside the component. Any internal feature (for example a defect or crack) located in the plane being interrogated will alter the amplitude of the ultrasonic signal and be displayed as a change in the color plotted on the monitor. The depth of the plane being evaluated is selected by time gating the ultrasonic signal. The distance that an ultrasonic pulse has traveled into a material depends on the velocity of sound and the time of flight. Thus a window in time is chosen that corresponds to the depth desired. In summary, the ultrasonic C-scan technique builds an image of a layer at a chosen depth from a set of ultrasonic pulse amplitudes captured at that depth. Figures B1, B2,and B3 illustrate the C-scan method for imaging defects.

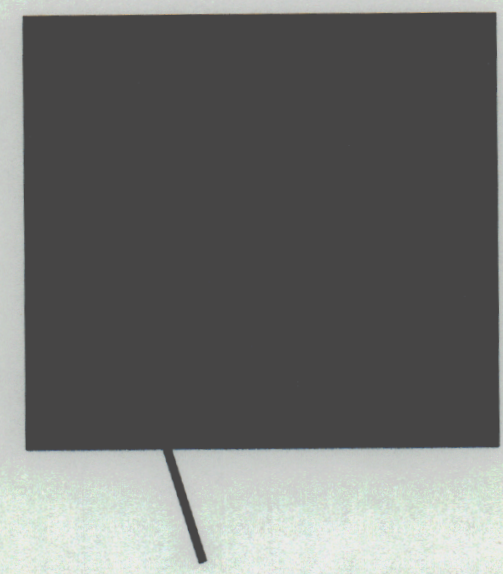

\section{Top view}

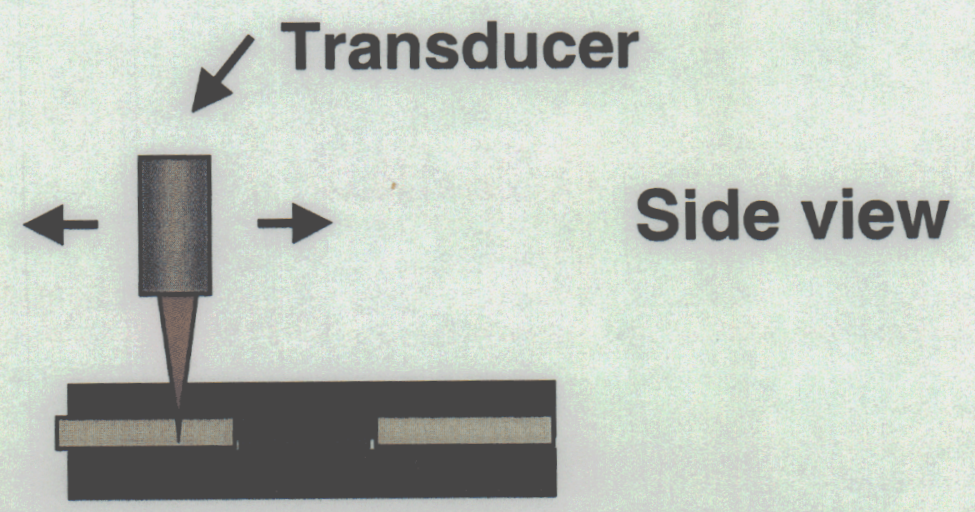

Figure B1. In ultrasonic C-scanning a transducer is raster scanned over the part 


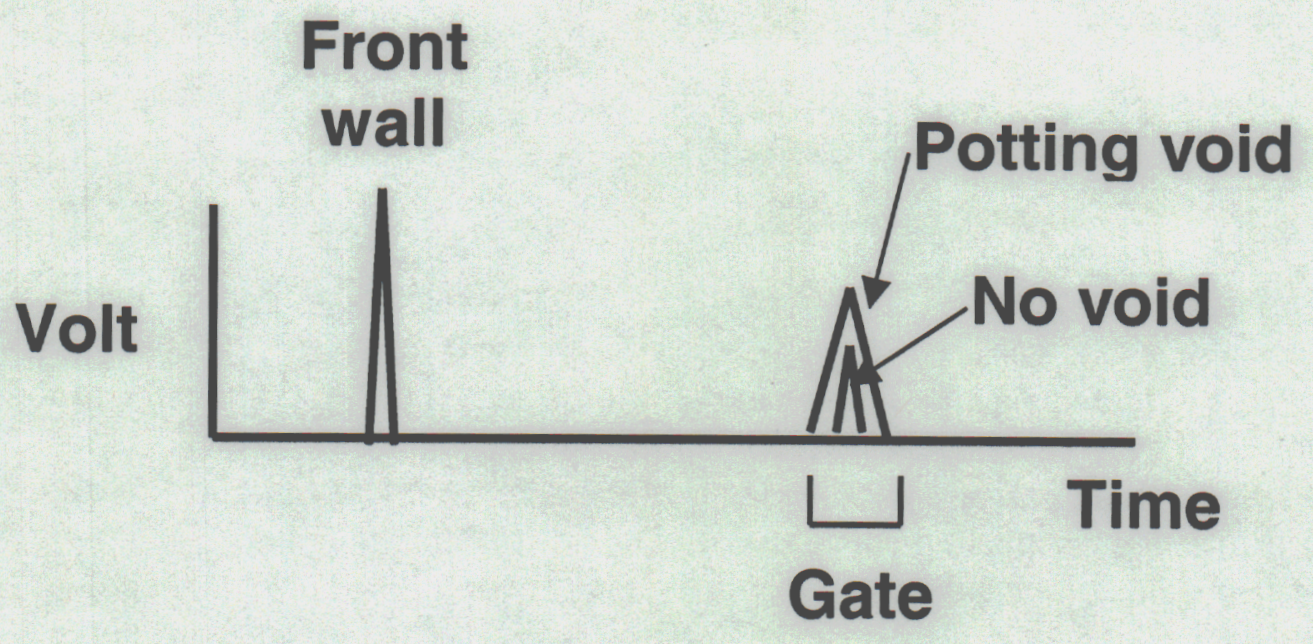

Figure B2. At each spatial location during a C-scan operation, the signal in a time gate is captured.



Figure B3. The amplitude of the ultrasonic signal in the time gate is converted to a color and the pixel corresponding to the transducer positon is displayed in that color. Thus a image of the potting void is generated (in this example gray represents a void). 